\title{
Wastewater Fines Influence the Adsorption Behavior of Pollutants onto Microplastics
}

\author{
Mitra Nikpay ${ }^{1}[0$ \\ Accepted: 12 July 2021 / Published online: 17 July 2021 \\ (c) The Author(s) 2021
}

\begin{abstract}
Millions of tons of microplastics (MPs) enter the wastewater collection systems every day and interact with raw sewage. In addition to MPs, varieties of organic and inorganic fines from urban effluents release into the sewer system and provide suitable surfaces for adsorption. To better understand the quantitative assessment of MPs sorption in wastewater and the role of fines, batch reactor experiments were performed using synthetic wastewater solutions containing organic, inorganic, and mixed organic-inorganic fines, and the results compared to a solution without fines. The MPs were two types of clean polypropylene (PP) particles, isotactic (iPP) and atactic (aPP). The results showed in all applied solutions the adsorption of pollutants was higher for the aPP averaging $1.3 \mathrm{mg} / \mathrm{g}$ compared with $0.5 \mathrm{mg} / \mathrm{g}$ for iPP, indicating that the adsorption varies with the type of polymer and surface properties. Further experiments also revealed a decrease in the sorption values of MPs for solutions containing inorganic fines, measured as the partition coefficient $\left(K_{d}\right)$ and adsorbed concentration at equilibrium $\left(\mathrm{q}_{\mathrm{e}}\right)$. The result of the measured reference conductivity $\left(\kappa_{25}\right)$ of the solutions for the same tests showed similar trends indicating that the magnitude of pollution adsorption onto MPs surfaces is controlled by the surface charge potential of the fine particles. The relationship between the qualitative assessments of ion removal, measured in terms of $\kappa_{25}$, and their quantitative assessment of adsorption values in terms of $\mathrm{K}_{\mathrm{d}}$ in several identical tests, verifying that the conductivity of the solution was modified after adsorption of wastewater constituents onto the MPs.
\end{abstract}

Keywords Polypropylene (PP) $\cdot$ Surfactants $\cdot$ Wastewater $\cdot$ Adsorption $\cdot$ Conductivity

\section{Introduction}

In urban areas, microplastics (MPs) of various sizes and shapes from polluted air, households, industries, and streets enter the wastewater collection system and combine with wastewater constituents [1-3]. That is the first interaction of MPs with raw sewage before entering the wastewater treatment facilities. The hydrophobic, non-polar surfaces of the MPs can adsorb wastewater contaminants which might significantly change their surface physicochemical properties as well as their size, density, and mobility in the fluid [4-8]. The microplastic particles have a relatively large surface area to volume ratio, and their hydrophobic surfaces support the adsorption of a wide variety of pollutants such as metals and organic chemicals [9-12].

Mitra Nikpay

nikpay11@gmail.com

1 Faculty of Civil Engineering, Dresden University of Applied Sciences, 01069 Dresden, Germany
Apart from MPs, other non-colloidal particles with small sizes $<63 \mu \mathrm{m}$ potentially enter the sewer system daily, especially during rainfall events [13-15]. This includes organic particles such as eggshells, seeds, coffee grounds, and bone chips and inorganic inert material such as sand, gravel, glass, cinder, and metal fragments [16]. Some of these particles have charged surfaces that serve as hosts for the adsorption of wastewater pollutants inside their abundant pores, cracks, cavity structures, and on the external surfaces. Regardless of the importance of the topic, it is yet not known how the fine particles in raw wastewater affect the adsorption of pollutants onto MPs surfaces.

In the wastewater matrix, a wide variety of ionic and organic sorptive compete for adsorption on the inorganic/ organic sorbents. The degree of adsorption for the ionic group is dominated by the magnitude of the electrical charges in both the sorptive and the sorbent. In the case of uncharged organic sorptive/sorbent which exhibits a range of polarities due to the distribution of electrons across molecules or surfaces, the adsorption behavior depends on the 
properties of the solution, e.g., $\mathrm{pH}$ or temperature, so they could exhibit ionic or nonionic behavior [17]. Furthermore, adsorption of wastewater constituents occurs on all surfaces, including the inner surfaces of the sewer pipe. The concentration of sorbed contaminants on the surfaces is controlled by the surface properties of sorbents and the sorption affinity of pollutants. Organic particles such as coffee grounds have an insoluble cellulose structure that makes them potential pollution sorbents [18]. The inorganic fines such as quartz with a silica-oxygen layer that inducing negative charges are more prone to adsorb charged sorptive [19, 20]. While adsorption processes between wastewater constituents and MPs surfaces in sewers depend on several factors, such as the nature of the interaction, mechanical variables, pollutant concentration, MPs shape, age, and density as well as the dynamics of adsorption at the interfaces [21-23].

Electrical conductivity is the qualitative parameter used to assess the ionic strength of the liquid phase [24, 25]. In wastewater, the liquid phase contains positive and negative ionic compounds and changes in response to variations in concentration. The conductivity of the liquid can be influenced either by adsorption or the participation of ions in chemical reactions. Hence, in a controlled operating system, conductivity could estimate the ion removal from the liquid phase of wastewater.

In brief, the main objective presented in this work focuses on the variation of the adhesion process of wastewater constituents obtained from three solutions containing organic, inorganic, or mixed organic-inorganic fines onto the two types of clean polypropylene (PP), isotactic (iPP), and atactic (aPP). Batch reactor tests were performed to demonstrate differences in adsorption on two polymer samples by comparing the results of three solutions with a fines-free fourth control solution. The results quantify the influence of the fines in the pollution adsorption onto the MPs surfaces. The tests were repeated for conductivity to measure the ion removal levels in the solutions and to assess the variation of electrical conductivity in a controlled system.

\section{Materials and Methods}

\section{Adsorbents and MPs}

For determining the adhesiveness of the synthetic wastewater components to the MPs, the bulk (WW) was prepared according to the contents outlined in Table 1. This solution comprised of stearic acid, palmitic acid, oleic acid, calcium chloride, iron oxide as $\mathrm{Fe}^{2+} / \mathrm{Fe}^{3+}$, and the surfactants as anionic sodium dodecylbenzene sulfonate (SDBS), cationic hexadecyl-trimethyl-ammonium bromide (CTAB), non-ionic Triton X-100, and all were purchased from Sigma Aldrich (Co.). The solution was prepared with
Table 1 Composition of synthetic wastewater bulk solution

\begin{tabular}{lll}
\hline Constituents & $\begin{array}{l}\text { Purity } \\
\%\end{array}$ & $\begin{array}{l}\text { Concentration } \\
\mathrm{mg} / \mathrm{L}\end{array}$ \\
\hline Stearic acid & 98.5 & 33 \\
Palmitic acid & 99 & 34 \\
Oleic acid & 99 & 33 \\
Anionic surfactant (SDBS) & 99 & 7.5 \\
Cationic surfactant (CTAB) & 98 & 1.5 \\
Non-ionic surfactant (TX100) & 95 & 10.2 \\
Calcium chloride & 97 & 74 \\
Iron oxide II/ III & 95 & 1 \\
\hline
\end{tabular}

Table 2 Composition of solutions applied in the tests

\begin{tabular}{lll}
\hline No. & Solution & Constituents \\
\hline 1 & WW & Bulk solution, 194.2 mg/L \\
2 & WWI & $273 \mathrm{mg}$ inorganic fines reached to $1.00 \mathrm{~L}$ of bulk \\
3 & WWO & $20 \mathrm{mg}$ organic fines reached to $1.00 \mathrm{~L}$ of bulk \\
4 & WWIO & $\begin{array}{c}273 \mathrm{mg} \text { inorganic fines }+20 \mathrm{mg} \text { organic fines } \\
\text { reached to } 1.00 \mathrm{~L} \text { of bulk }\end{array}$ \\
\hline
\end{tabular}

deionized water and mixed in an ultrasonic cleaner for $45 \mathrm{~min}$ and placed in a preheated oven at $70{ }^{\circ} \mathrm{C}$ for $5 \mathrm{~min}$ to ensure the homogeneous melt of blended triglycerides compounds [8].

To prepare the solutions used in the batch tests and to model the condition of a sewer system, the liquid phase (bulk solution, WW, Table 1) was mixed with a solid phase containing organic and inorganic fines (see Table 2). The second solution (WWI) was prepared using $273 \mathrm{mg}$ fine inorganic white quartz with a size ranging from 210 to $297 \mu \mathrm{m}$ purchased from Sigma Aldrich Co., poured into the volumetric balloon, and the bulk solution was added until the volume of $1000 \mathrm{ml}$ obtained. The third solution (WWO) was composed of coffee particles with a size of $100 \mu \mathrm{m}$ after coffee beans were ground and sieved, and a weight of $20 \mathrm{mg}$ of particles reached the volume of $1000 \mathrm{ml}$ of the bulk. Finally, the fourth solution (WWIO) was the mixed inorganic quartz of $273 \mathrm{mg}$ with organic coffee particles of $20 \mathrm{mg}$ was reached the volume of $1000 \mathrm{ml}$ of the bulk.

The MPs particles are two types of PP polymers, isotactic (iPP) and atactic (aPP) which were purchased from Sigma Aldrich (Co.). The clean granular samples of polymers have an average size of $\sim 5 \mathrm{~mm}$ with a density of $0.9 \mathrm{~g} / \mathrm{ml}$ and 0.93 for aPP and iPP, respectively. Both polymers are semi-transparent materials with white color. For the rubbery aPP, the methyl groups appear randomly along the polymer molecular chain, while in the crystalline iPP, the methyl groups are positioned on only one side of the polymer molecular chain. 


\section{Batch Experiments and Adsorption Model}

Batch experiments were conducted to determine the adsorption model of wastewater constituents onto the aPP and iPP particles. For four different groups of solutions listed in Table 2, with three identical samples, 12 batches were conducted. Hence, a total of 24 batches were counted for two individual experiments using two polymer samples. The glass bottles were filled with $20 \mathrm{ml}$ of each solution and capped to avoid contact with the environment. The clean polymer samples of aPP and iPP were added to the bottles weighed using the METTLER TOLEDO AT261 DeltaRange analytical scale with the readability of $0.01 \mathrm{mg}$ and linearity of $\pm 0.08 \mathrm{mg}$. Finally, the bottles were placed on an IKA Vibrax VXR vibrator with orbital motions of $180 \mathrm{rpm}$ for $168 \mathrm{~h}$. The shaking rate throughout the experiment allowed the surfaces of the MPs samples to meet the wastewater constituents. After $168 \mathrm{~h}$, the MPs particles were removed from the solutions using a micro scoop and placed in a clean glass petri dish. Then, the samples were placed in an oven at $35^{\circ} \mathrm{C}$ for $20-30 \mathrm{~min}$ [26]. The dried MPs were kept in a desiccator for $1 \mathrm{~h}$ to reach room temperature and protect the samples from moisture. The dry weight of the polymer sample subtracted from its weight after the test, shows the weight differences and thus the weight of adsorbed pollutants onto the tested polymer. The average values of three identical tests derived from the difference in weight of iPP and aPP samples before and after interaction with solutions was used for further calculations. The $\mathrm{pH}$ value of the solutions was measured using WTW Multiline P4. The results showed no significant change in the $\mathrm{pH}$ of solutions and $\mathrm{read} \sim 7.14 \pm 0.01$ at a temperature of $\sim 20^{\circ} \mathrm{C}$. Also, the MPs samples were inspected using the stereomicroscope Müller $\mathrm{GmbH}$ equipped with a digital camera DCM310. The taken images were analyzed for further pollutant adsorption onto the MPs surfaces.

In the batch experiments, the quantity of the adsorbed constituents at the unit mass of the adsorbent at equilibrium $\mathrm{q}_{\mathrm{e}}$ is calculated as:

$q_{e}=\frac{c_{i}-c_{f}}{m_{i}} \times V$

where $c_{i}$ is the initial concentration of solution and $c_{f}$ is the equilibrium concentration of the solution in $\mathrm{mg} / \mathrm{L}, \mathrm{m}_{\mathrm{i}}$ is the mass of the dry adsorbent $(\mathrm{g})$ and $\mathrm{V}$ is the solution volume (L). Since the variation in concentration of the solution correlates directly with the adsorption on the adsorbent, the following expression is obtained:

$\left(c_{i}-c_{f}\right) V=m_{f}-m_{i}$

where $m_{i}$ is the initial mass and $m_{f}$ is the final mass of MPs particles in $\mathrm{mg}$ at test. Using Eq. 2, Eq. 1 can be expressed as follows: $q_{e}=\frac{\left(m_{f-} m_{i}\right)}{m_{i}}$

Hence, the partition coefficient, $K_{d}$, as the ratio of adsorbed wastewater constituents on the MPs surfaces is calculated for this experiment as:

$K_{d} \approx \frac{q_{e}}{C_{e}}$

where $\mathrm{q}_{\mathrm{e}}$ is the amount of adsorbed wastewater constituents on the MPs surfaces (mg/g) and $c_{e}$ is the equilibrium concentration of pollutants in the solution $(\mathrm{mg} / \mathrm{ml})$.

\section{Electrical Conductivity}

The electrical conductivity was measured using a WTW Multiline P4. The instrument was calibrated by two methods, using standard solutions recommended by the manufacturer and by comparing the results with another conductivity meter from the same company. Electrical conductivity is a function of various factors such as ionic strength of the solution, concentration, mobility, valence, and temperature. For this experiment, concentrations of solutions were prepared according to Table 2 and performed as described for the batch experiments. The temperature of the samples was measured $20 \pm 0.5^{\circ} \mathrm{C}$. Using a conductivity meter and probe, the electrical conductivity of a solution, $\kappa$, can be measured according to the equation:

$\kappa=K_{\text {cell }} G$

where $\mathrm{K}_{\text {cell }}$ is the constant of the conductivity cell and $\mathrm{G}$ is the conductance. The $\mathrm{K}_{\text {cell }}$ is considered as a constant ratio between the conductivity of the cell plate and the area of the plate. The reference conductivity $\kappa_{25}$ is the conductivity at $25{ }^{\circ} \mathrm{C}$ because the conductivity increases $1 \%$ to $3 \%$ per ${ }^{\circ} \mathrm{C}$ [27]. Equation 6 is used to calculate $\kappa_{25}$ :

$\kappa_{25}=\frac{\kappa}{1+\alpha\left(t-25^{\circ} \mathrm{C}\right)}$

where $\kappa$ is the conductivity $(\mu \mathrm{S} / \mathrm{cm})$ at temperature $t\left({ }^{\circ} \mathrm{C}\right)$ and $\alpha$ is the temperature compensation factor which varies between 0.019 and $0.020^{\circ} \mathrm{C}^{-1}$.

\section{Results and Discussion}

\section{Adsorption Kinetics in Batch Experiment}

Batch reactor experiments were conducted to simulate the interaction of the polymer samples with the liquid phase of the wastewater at identical conditions/or negligible variation of $\mathrm{pH}$, temperature, concentration, and contact time 
using four solutions characterized in Table 2. In other words, for the identically designed batch tests, the only variation occurred in the solid phase content. Figure 1 shows the average results of three identical tests in four synthetic wastewater solutions comparing the differences in adsorption of pollutants onto the aPP and iPP particles. The measured adsorption coefficient $\mathrm{K}_{\mathrm{d}}$ is defined as the volumetric adsorption of pollutants by the bulk (WW), bulk with inorganic fines (WWI), bulk with organic fines (WWO), and bulk with mixed organic-inorganic fines (WWIO) on the polymer samples and expressed in $\mathrm{ml} / \mathrm{g}$. The adsorption coefficient value for aPP shows an average of $6.9 \mathrm{ml} / \mathrm{g}$ for the tested solutions compared to the average value of $2.4 \mathrm{ml} / \mathrm{g}$ for iPP (Fig. 1a), implying that there is a considerable increase in the adsorption potential for the aPP after interaction with solutions.
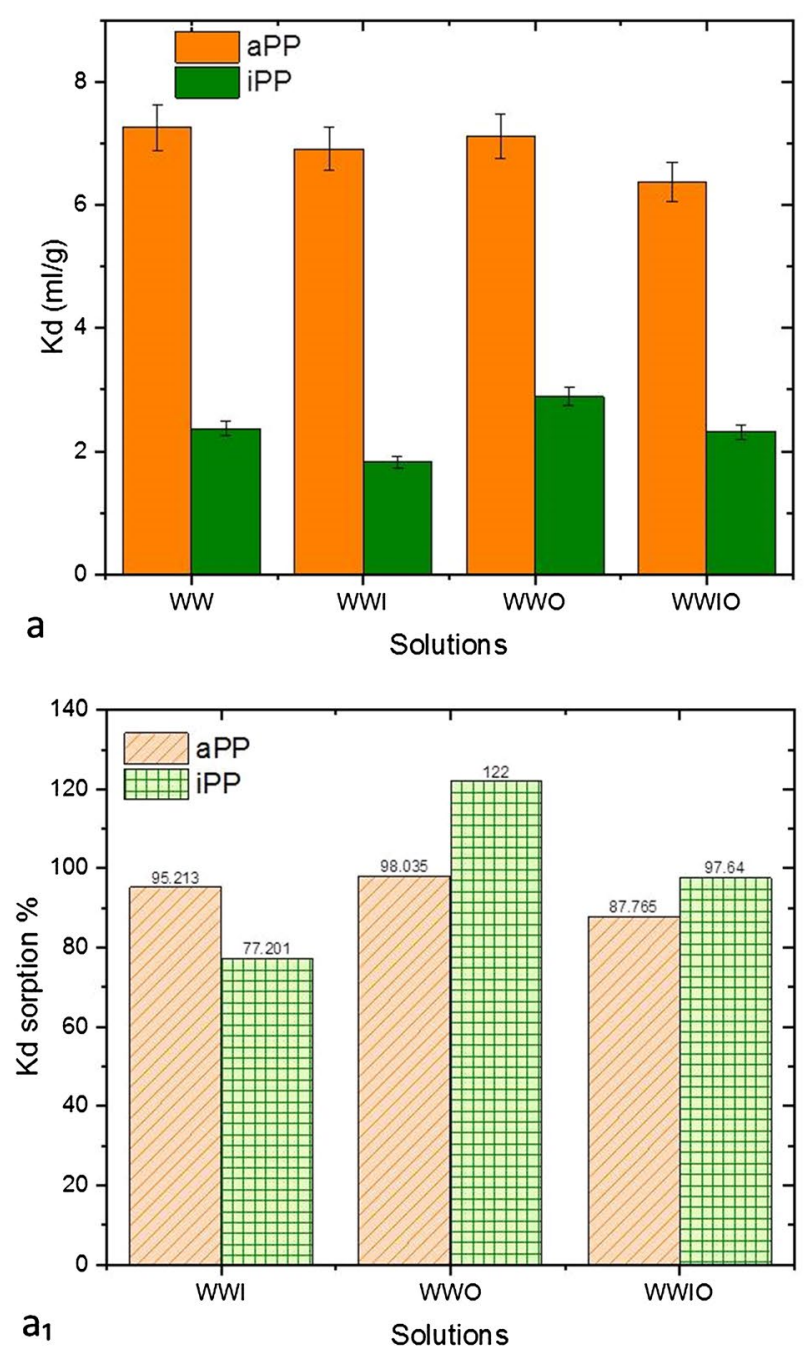

Fig. 1 Adsorption of pollutants onto the iPP and aPP samples described as a function of $\mathbf{a}$ partition coefficient $K_{d}$ and $\mathbf{b}$ quantity of the adsorbed constituents $\mathrm{q}_{\mathrm{e}}$ at equilibrium within four synthetic wastewater solutions with standard errors. The plots of tested $\mathbf{a}_{\mathbf{1}} \mathrm{K}_{\mathrm{d}}$
Figure $1 \mathrm{~b}$ indicates the pollution adsorption value $\mathrm{q}_{\mathrm{e}}$ obtained for the same experiments. The results show that the adsorption onto the aPP samples in the bulk solution with a value of $1.4 \mathrm{mg} / \mathrm{g}$ is the highest among the four solutions. This adsorption for a solution with organic fines, WWO, indicated a slight decrease to $1.38 \mathrm{mg} / \mathrm{g}$ compared to the bulk, while the greatest decrease was observed in the presence of mixed organic-inorganic fines, WWIO, with a value of $1.2 \mathrm{mg} / \mathrm{g}$. The maximum pollution adsorption for the iPP was obtained from a solution with organic fines, WWO, at a value of $0.56 \mathrm{mg} / \mathrm{g}$. The bulk and WWIO with a value $\sim 0.45 \mathrm{mg} / \mathrm{g}$ shared the same values of adsorption while WWI with inorganic fines obtained lower adsorption of about $0.36 \mathrm{mg} / \mathrm{g}$.

As previously noted, there is higher pollutant adsorption of WWO onto the iPP compared to its adsorption
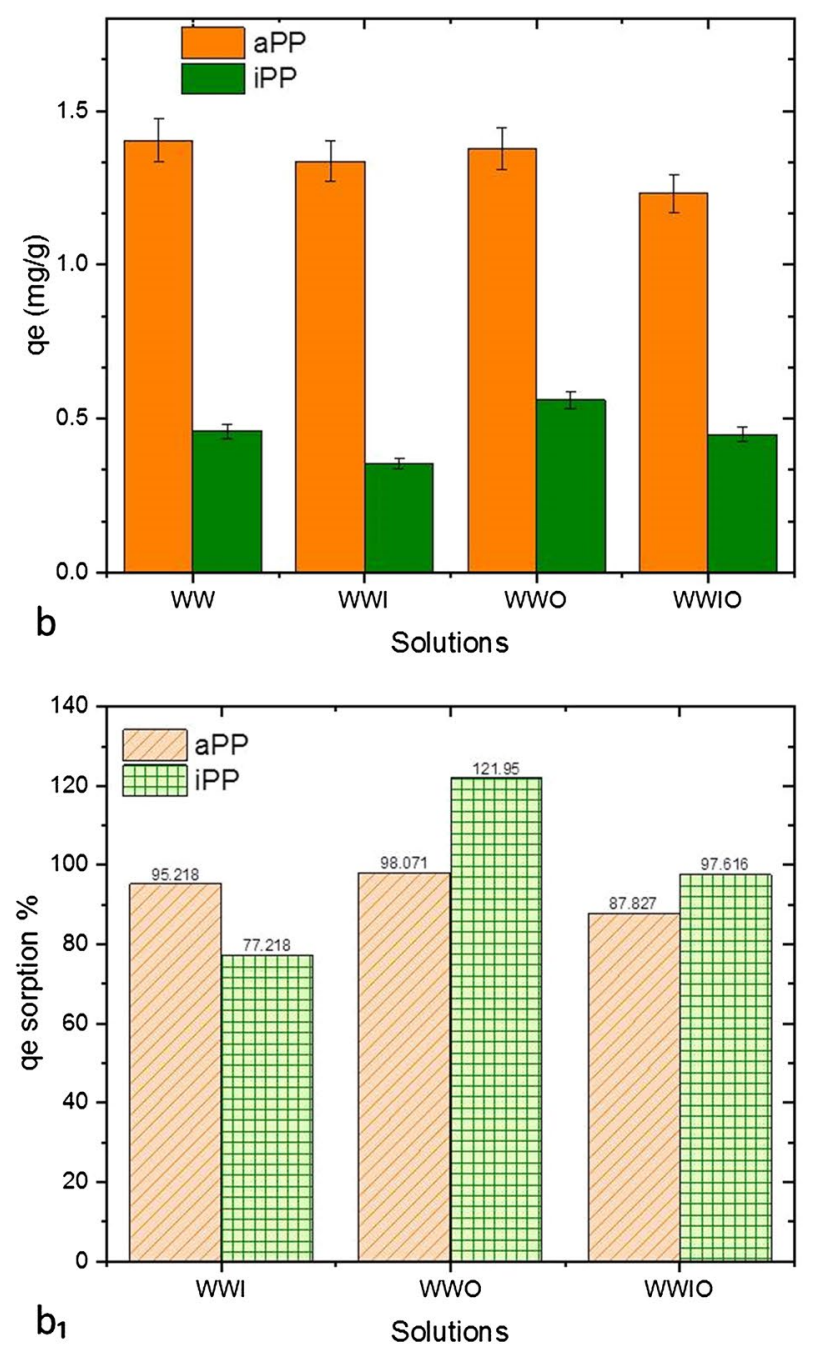

and $\mathbf{b}_{\mathbf{1}} \mathrm{q}_{\mathrm{e}}$ which representing the solution's adsorption percentage in relative to the bulk as the reference, were derived from plots $\mathrm{a}$ and $\mathrm{b}$, respectively 
rate from the bulk (see Fig. 1a, b). This additional weight resulted from the direct adsorption of organic particles onto the iPP surfaces, emphasizing the high affinity of this polymer for the adsorption of hydrophobic organic particles. The coffee particles contained lipids that consist mainly of triacylglycerols, sterols, and the typical components of all common edible vegetable oils [28]. The hydrophobic adsorption between the molecules of lipids in bulk and the coffee particles induced the binding of free lipids to the coffee particles and consequently boosted their hydrophobicity. Thus, the aggregated lipids improved the tendency of the organic particles to adsorb on polymer surfaces.

As shown in Fig. 1a, b, the low adsorption rate on the polymer samples in solutions with inorganic fines indicates that $\mathrm{SiO}_{2}$ is an ideal host for the adsorption of pollutants. The quartz particles with negative surface charges allow adsorption of cationic CTAB molecules, and their heads interact only weakly with the particle surfaces [29]. This poor adsorption allows indirect adsorption of anionic SDS by electrostatic interaction. Consequently, the pairs of cationic/anionic surfactants with heads toward the quartz surfaces and tails inside the liquid increase the hydrophobicity of the surfaces, which enhances the adsorption of pollutants on the quartz [30]. The modified hydrophobic surfaces of quartz tend to adsorb molecules of lipids and eventually led to its adhesion on the polymer's surfaces.
Figure 1a1, b1 illustrates the relationship between the adsorption capacities of the aPP and iPP particles using the solutions listed in Table 2, where the bulk solution was used as a reference for comparison with the results of the solutions containing fines. From the plots, the adsorption percentage of the solutions with organic fines was excellent for the polymer samples with a maximum of $\sim 122 \%$ for the iPP, implying that organic particles tend to adsorb directly on the particle surfaces. For solutions containing inorganic particles, the adsorbent indicated a minimum for the polymer samples, $\sim 77 \%$ for the iPP, signifying that, inorganic fines compete with the MPs particles for adsorption of bulk constituents, thus reducing the adsorption efficiency of the MPs.

Figure $2 \mathrm{a}, \mathrm{b}$ represents a closer view of the adsorbed pollutants on the aPP and iPP surfaces. The microscopic images of the polymer samples after $168 \mathrm{~h}$ of interaction with wastewater solutions were compared to a clean control sample. It is evident that the aPP surfaces are mainly characterized by hills and gaps, and the iPP is characterized by grooves and cavities. The wastewater constituents aggregated mainly near the hills and inside cavities in both polymer samples (Fig. 2a, b). The adsorption of dispersed pollutants, particularly dark iron on the aPP surfaces, is shown for WW in Fig. 2a. More aggregated micro-colonies of wastewater constituents were formed on the aPP surfaces for WWI and WWIO. Likewise, the pollution distribution for WWO with organic fines exhibits a similar appearance

a
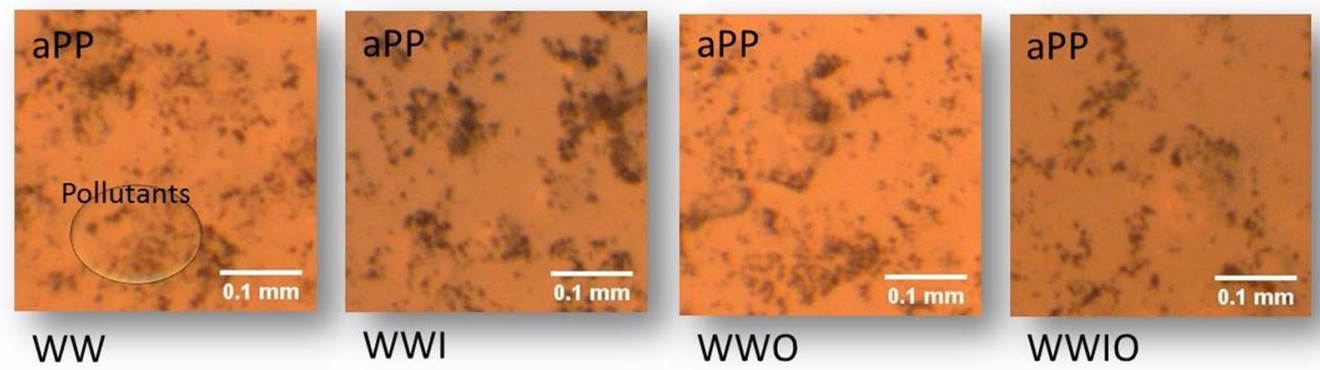

aPP

b
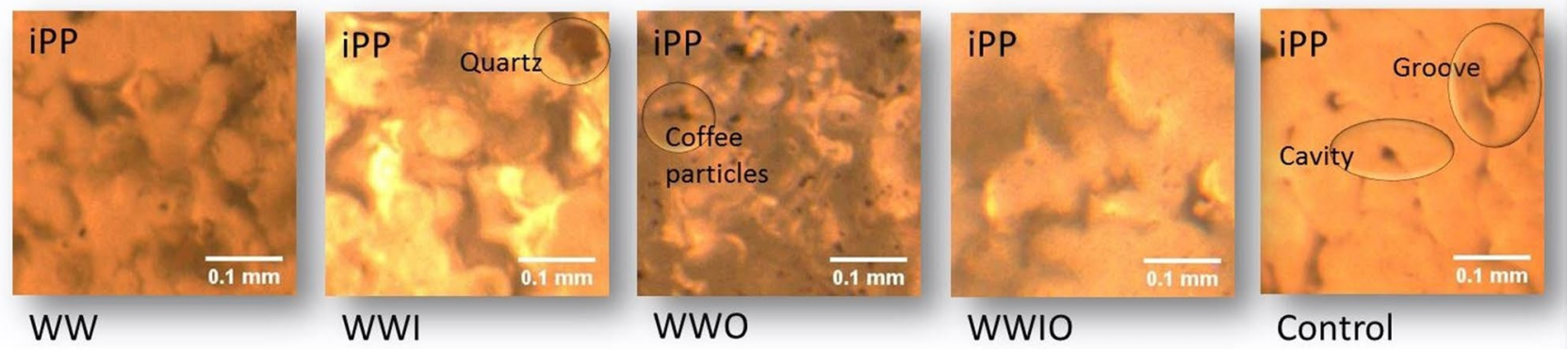

Fig. 2 Adsorbed pollutants from four wastewater solutions onto the surfaces of two polymers a aPP and $\mathbf{b}$ iPP. The dry clean control samples were compared with the tested samples 
to WW. Figure $2 \mathrm{~b}$ shows that pollutants accumulated mainly inside the iPP cavities, which is more evident in the WWO image. There are also adsorbed inorganic fines/quartz on the iPP, which is shown in the WWI image. Further images of iPP sample reveal that organic particles were successfully trapped or adsorbed inside the cavities for WWO, while particle adsorption is not successful enough for WWIO.

From the microscopic examination of the images, it is evident that the adsorption of constituents could significantly change the surface roughness, wetting properties, and chemical composition of the polymer surfaces. Also, the adhesion and retention of particles such as $\mathrm{Fe}$ on the polymer surfaces could increase the average roughness of the substrate and thus promote the adhesion of more particles.

\section{Conductivity and Adsorption}

The model batch reactors were set up with the solutions listed in Table 2 and carried out for the polymer samples aPP and iPP to measure the reference conductivity at $25^{\circ} \mathrm{C}$ $\left(\kappa_{25}\right)$. Figure 3a illustrates the average results of three $\kappa_{25}$ tests (see Eq. 6) in four applied solutions containing aPP and iPP samples compared to a control solution without polymers. The changes in $\kappa_{25}$ values in WW for both polymers show alignment with the control solution, while a low value of $175.3 \mu \mathrm{S} / \mathrm{cm}$ and $175.9 \mu \mathrm{S} / \mathrm{cm}$ was obtained for WWI with aPP and iPP, respectively. The $\kappa_{25}$ shows no changes in WWO for iPP $(177.3 \mu \mathrm{S} / \mathrm{cm})$ with a slight decrease for aPP at $176.4 \mu \mathrm{S} / \mathrm{cm}$. However, the conductivity changes are greater in WWIO having aPP and iPP at $176.5 \mu \mathrm{S} / \mathrm{cm}$ and $176.8 \mu \mathrm{S} / \mathrm{cm}$, respectively.

Figure $3 \mathrm{~b}$ shows $\kappa_{25}$ percentage in solutions with aPP and iPP samples in comparison with a polymer-free solution. The plot shows the ionic strength is highest in the liquid without fines (WW). This is because fewer charged surfaces are available for ionic adsorption of pollutants, and thereby the ionic strength remains intact. The lowest ionic strength is $\sim 99.3 \%$ for the solution containing inorganics (WWI), implying that more ion adsorption is available on the charged surfaces of quartz particles, which leads to a decrease in the ionic strength of the solution.

Figure 4 shows the measured $\kappa_{25}$ versus the values of $\mathrm{k}_{\mathrm{d}}$ (see Fig. 1) to draw a comparison between the results of two methods and their relationships. From the plot, the similar trends in the quantity of conductivity as $\kappa_{25}$ values of four solutions containing MPs versus the plot of adsorption as $\mathrm{k}_{\mathrm{d}}$ are evident. The plot shows the correlation between the conductivity of the solutions and the adsorption of components onto the polymer surfaces [31]. Consequently, if the measured $\kappa_{25}$ shows a decrease relative to a control solution, this implies that the adsorption of components onto the MPs surfaces exhibits an increase in their weights.

A Spearman and Kendall correlation was performed to determine the statistical correlation coefficient between the $K_{d}$ and $K_{25}$ values for aPP and iPP samples from the four solutions. The results showed a strong positive correlation between $\mathrm{K}_{\mathrm{d}}$ and $\mathrm{K}_{25}$ for iPP as $\mathrm{r}_{\mathrm{s}}$ (Spearman's correlation) of $0.6, p$ (probability value) of 0.4 , and a very strong correlation, $\mathrm{r}_{\mathrm{s}}$ of $0.8, \mathrm{p}$ of 0.2 for the aPP. The Kendall's Tau, $\tau$, also exhibits moderate to strong correlation and was found to be 0.333 with a p of 0.5 for the iPP and $\tau$ of $0.667, p$ of 0.17 for the aPP. Nevertheless, the p-value obtained by the sample size and can yield statistically significant outcomes when the sample size is larger.

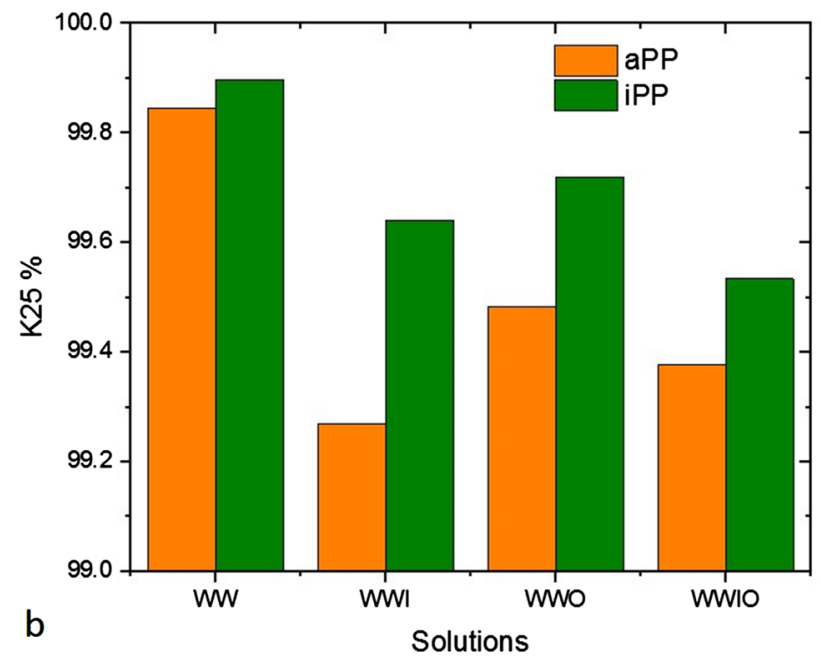

Fig. 3 a Dissolved ions as a function of reference conductivity at $25^{\circ} \mathrm{C}, \kappa_{25}$, in four synthetic wastewater solutions after interaction with the iPP and aPP samples and comparison with the solution without polymer. Plot $\mathbf{b}$ is the percentage of $\kappa_{25}$ for tested ionic strength of the plot (a) 
Fig. 4 Plots representing the variations in ionic composition of four synthetic wastewater solutions recognized as reference conductivity at $25^{\circ} \mathrm{C}, \mathrm{K}_{25}$, versus variation in pollution adsorption as $\mathrm{K}_{\mathrm{d}}$, were obtained in identical distinct experiments

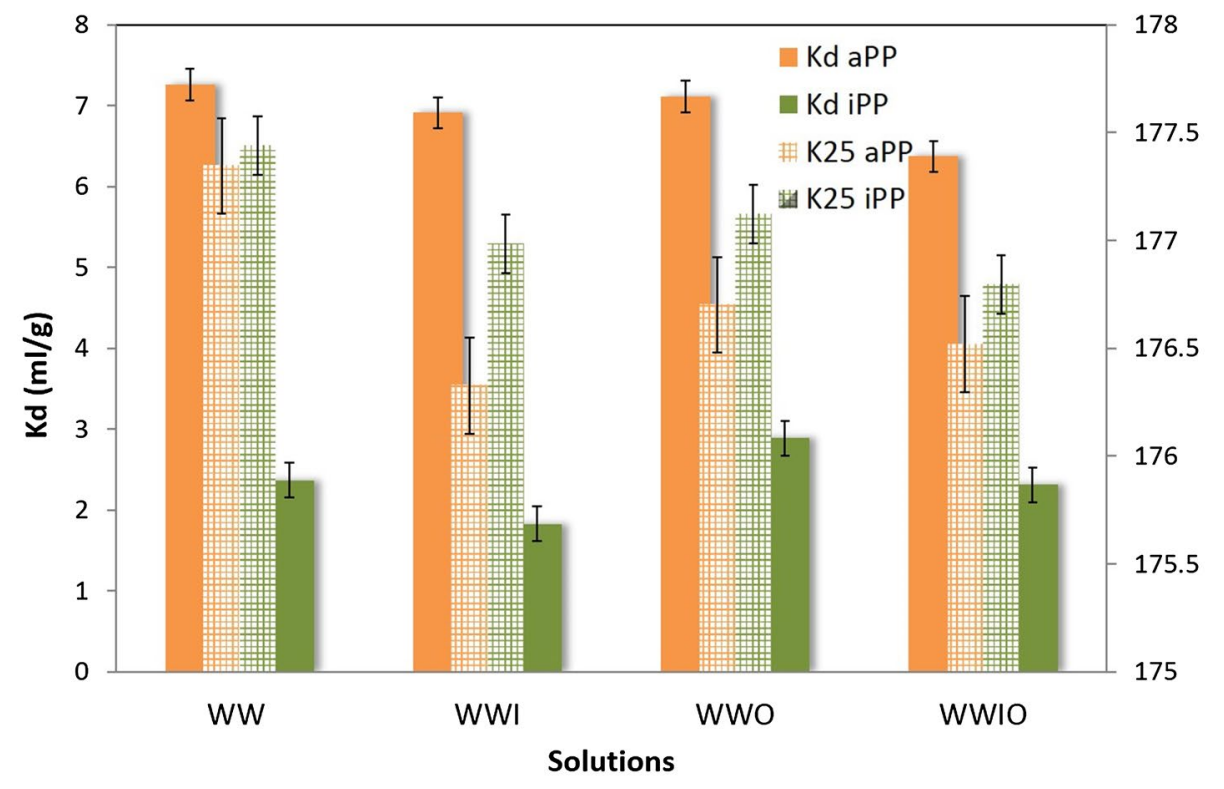

Accordingly, the qualitative results of conductivity in this study can estimate the adsorption process from the solution onto the MPs solid surfaces in a controlled system. However, for an uncontrolled system, this method is not viable due to the electrical conductivity broader variation in natural wastewater flow as well as the impact of bacterial degradations.

\section{Conclusion}

The present study investigated the interaction of two types of PP-based polymers, namely crystalline iPP and amorphous aPP in three synthetic wastewater solutions containing organic, inorganic, and mixed organic-inorganic fines through a series of controlled batch reactors to compare the results with a reference solution.

The findings of pollutant adsorption onto the aPP and iPP in terms of $\mathrm{K}_{\mathrm{d}}$ and $\mathrm{q}_{\mathrm{e}}$ showed a different adsorption pattern which was higher for aPP. The microscopic images of polymer samples confirmed a difference in the aggregation of pollutants on the aPP and iPP surfaces with more appearance near the hills and inside the pores. It was also found that the adsorption of constituents onto the aPP and iPP samples were lower for solutions with inorganic fines. The results of electrical conductivity measurement as $\kappa_{25}$ indicate that this qualitative factor could be used as an initial assessment of the adsorption process onto MPs surfaces in a controlled system.

In summary, the adsorption of wastewater constituents onto the MPs surfaces alters their surface properties and makes MPs a perfect host for the collection and transport of hazardous substances.

Acknowledgements The author would like to thank Prof. Dr.-Ing. Thomas Grischek for his guidance and valued scientific advice in the preparation of the manuscript. The author thanks the HelmholtzZentrum Dresden-Rossendorf (HZDR) to allow using the laboratory equipment of this institution. This work was supported by the SAB (Microplastic Separator Project, No. 716052121).

Funding Open Access funding enabled and organized by Projekt DEAL.

Open Access This article is licensed under a Creative Commons Attribution 4.0 International License, which permits use, sharing, adaptation, distribution and reproduction in any medium or format, as long as you give appropriate credit to the original author(s) and the source, provide a link to the Creative Commons licence, and indicate if changes were made. The images or other third party material in this article are included in the article's Creative Commons licence, unless indicated otherwise in a credit line to the material. If material is not included in the article's Creative Commons licence and your intended use is not permitted by statutory regulation or exceeds the permitted use, you will need to obtain permission directly from the copyright holder. To view a copy of this licence, visit http://creativecommons.org/licenses/by/4.0/.

\section{References}

1. Bayo J, Olmos S, López-Castellanos J (2020) Microplastics in an urban wastewater treatment plant: the influence of physicochemical parameters and environmental factors. Chemosphere 238:124593

2. Blair RM, Waldron S, Gauchotte-Lindsay C (2019) Average daily flow of microplastics through a tertiary wastewater treatment plant over a ten-month period. Water Res 163:114909

3. Narmadha VV, Jose J, Patil S, Farooqui MO, Srimuruganandam B, Saravanadevi S, Krishnamurthi K (2020) Assessment of 
microplastics in roadside suspended dust from urban and rural environment of Nagpur. India Int J Environ Res 14(6):629-640

4. Guo X, Pang J, Chen S, Jia H (2018) Sorption properties of tylosin on four different microplastics. Chemosphere 209:240-245

5. Wanner P (2020) Plastic in agricultural soils-a global risk for groundwater systems and drinking water supplies?-a review. Chemosphere. https://doi.org/10.1016/j.chemosphere.2020. 128453

6. Godoy V, Martín-Lara MA, Calero M, Blázquez G (2020) The relevance of interaction of chemicals/pollutants and microplastic samples as route for transporting contaminants. Process Saf Environ Prot 138:312-323

7. Wang F, Zhang M, Sha W, Wang Y, Hao H, Dou Y, Li Y (2020) Sorption behavior and mechanisms of organic contaminants to nano and microplastics. Molecules 25(8):1827

8. Nikpay M, Eqtesadi S, Krebs P (2020) Influence of synthetic wastewater on entrapped air on the isotactic and atactic polypropylene microplastic surfaces. J Environ Health Sci Eng 18(2):1569-1579

9. Kolská Z, Makajová Z, Kolářová K, Slepičková NK, Trostová S, Řezníčková A, Siegel J, Švorčík V (2013) Electrokinetic potential and other surface properties of polymer foils and their modifications. Polym Sci 4:203-228

10. Li X, Mei Q, Chen L, Zhang H, Dong B, Dai X, He C, Zhou J (2019) Enhancement in adsorption potential of microplastics in sewage sludge for metal pollutants after the wastewater treatment process. Water Res 157:228-237

11. Vockenberg T, Wichard T, Ueberschaar N, Franke M, Stelter M, Braeutigam P (2020) The sorption behaviour of amine micropollutants on polyethylene microplastics-impact of aging and interactions with green seaweed. Environ Sci Process Impacts 22(8):1678-1687

12. Hakim A, Kobayashi M (2021) Aggregation and aggregate strength of microscale plastic particles in the presence of natural organic matter: effects of ionic valence. J Polym Environ 29:1-9

13. Crabtree RW (1989) Sediments in sewers. Water Environ J 3(6):569-578

14. Taylor KG, Owens PN (2009) Sediments in urban river basins: a review of sediment-contaminant dynamics in an environmental system conditioned by human activities. J Soils Sediments 9(4):281-303

15. Owens PN, Caley KA, Campbell S, Koiter AJ, Droppo IG, Taylor KG (2011) Total and size-fractionated mass of road-deposited sediment in the city of Prince George, British Columbia, Canada: implications for air and water quality in an urban environment. $\mathrm{J}$ Soils Sediments 11(6):1040-1051

16. Kim JY, Sansalone JJ (2008) Event-based size distributions of particulate matter transported during urban rainfall-runoff events. Water Res 42(10-11):2756-2768
17. Thompson A, Goyne KW (2012) Introduction to the sorption of chemical constituents in soils. Nat Educ Knowl 4(4):7

18. Hao L, Wang P, Valiyaveettil S (2017) Successive extraction of As (V), $\mathrm{Cu}$ (II) and $\mathrm{P}(\mathrm{V})$ ions from water using spent coffee powder as renewable bioadsorbents. Sci Rep 7(1):1-12

19. Forbes E, Franks GV (2013) Selective separation of hematite from quartz by flotation using a temperature responsive polymer. In Proc. Iron Ore Conference. 12-14 August 2013, AusIMM Perth, Australia

20. Habibi A, Dehghanpour H (2018) Wetting behavior of tight rocks: from core scale to pore scale. Water Resour Res 54(11):9162-9186

21. Razanajatovo RM, Ding J, Zhang S, Jiang H, Zou H (2018) Sorption and desorption of selected pharmaceuticals by polyethylene microplastics. Mar Pollut Bull 136:516-523

22. Godoy V, Blázquez G, Calero M, Quesada L, Martín-Lara MA (2019) The potential of microplastics as carriers of metals. Environ Pollut 255:113363

23. Wang T, Yu C, Chu Q, Wang F, Lan T, Wang J (2020) Adsorption behavior and mechanism of five pesticides on microplastics from agricultural polyethylene films. Chemosphere 244:125491

24. Hayashi M (2004) Temperature-electrical conductivity relation of water for environmental monitoring and geophysical data inversion. Environ Monit Assess 96(1-3):119-128

25. Pawlowicz R (2008) Calculating the conductivity of natural waters. Limnol Oceanogr Methods 6(9):489-501

26. Kim JH, Ahn SI, Kim JH, Zin WC (2007) Evaporation of water droplets on polymer surfaces. Langmuir 23(11):6163-6169

27. McCleskey RB, Nordstrom DK, Ryan JN (2012) Comparison of electrical conductivity calculation methods for natural waters. Limnol Oceanogr Methods 10(11):952-967

28. Speer K, Kölling-Speer I (2006) The lipid fraction of the coffee bean. Braz J Plant Physiol 18(1):201-216

29. Tyrode E, Rutland MW, Bain CD (2008) Adsorption of CTAB on hydrophilic silica studied by linear and nonlinear optical spectroscopy. J Am Chem Soc 130(51):17434-17445

30. Zhang R, Xing Y, Xia Y, Guo F, Ding S, Tan J, Che T, Meng F, Gui X (2020) Synergistic adsorption mechanism of anionic and cationic surfactant mixtures on low-rank coal flotation. ACS Omega 5(32):20630-20637

31. Anderson JH Jr, Parks GA (1968) Electrical conductivity of silica gel in the presence of adsorbed water. J Phys Chem 72(10):3662-3668

Publisher's Note Springer Nature remains neutral with regard to jurisdictional claims in published maps and institutional affiliations. 